\title{
Sulfamethoxazole-Trimethoprim-Induced Rhabdomyolysis in an Immunocompetent Patient: A Case Report
}

\author{
Pamela M. Moye ${ }^{1,2^{*}}$, Sara Manasen ${ }^{3}$, Kristen 0’Brien ${ }^{1,2}$ \\ ${ }^{1}$ Department of Pharmacy Practice, Mercer University College of Pharmacy, Atlanta, GA, USA \\ ${ }^{2}$ WellStar Atlanta Medical Center, Atlanta, GA, USA \\ ${ }^{3}$ Mercer University College of Pharmacy, Atlanta, GA, USA \\ Email: *moye_pm@mercer.edu
}

How to cite this paper: Moye, P.M., Manasen, S. and O'Brien, K. (2017) Sulfamethoxazole-Trimethoprim-Induced Rhabdomyolysis in an Immunocompetent Patient: A Case Report. Case Reports in Clinical Medicine, 6, 311-316.

https://doi.org/10.4236/crcm.2017.612037

Received: September 21, 2017

Accepted: December 19, 2017

Published: December 22, 2017

Copyright (c) 2017 by authors and Scientific Research Publishing Inc. This work is licensed under the Creative Commons Attribution International License (CC BY 4.0).

http://creativecommons.org/licenses/by/4.0/

\begin{abstract}
Sulfamethoxazole-trimethoprim (TMP-SMX)-induced rhabdomyolysis is a rare complication of a commonly used antibiotic. This is a case report of a 43-year old immunocompetent African American woman with a history of depression and chronic alcohol consumption who presented to the emergency department (ED) with worsening bilateral leg pain. Before presentation, the patient was prescribed a twice daily dose of TMP-SMX for a urinary tract infection. The patient reported the development of intensifying leg pain after taking five doses of TMP-SMX. On presentation to the ED she was hemodynamically stable, afebrile, and leg pain intensity 10 out of 10 . The patient admitted to daily alcohol consumption and taking vortioxetine $10 \mathrm{mg}$ per day for treatment of depression. Initial labs drawn in the ED showed an elevated creatine kinase (CK) of 26,231 U/L and a normal serum creatinine (SCr) of 1 $\mathrm{mg} / \mathrm{dL}$. Through patient history and laboratory tests, common causes of rhabdomyolysis were ruled out. Treatment was initiated with IV fluids plus thiamine and folic acid supplementation, TMP-SMX was discontinued, and vortioxetine $10 \mathrm{mg}$ per day was continued until hospital day five. The patient began to show improvement in lower extremity pain and tenderness and was discharged on hospital day eight with minimal residual leg pain and a CK of 2809 U/L. This case report presents only the third incidence of an immunocompetent patient developing TMP-SMX-induced rhabdomyolysis. This case highlights an opportunity for a pharmacist's intervention and the need for future research to determine risk factors of TMP-SMX-induced rhabdomyolysis in immunocompetent patients.
\end{abstract}

\section{Keywords}

Rhabdomyolysis, Sulfamethoxazole-Trimethoprim, Immunocompetent 


\section{Introduction}

Rhabdomyolysis is a syndrome of skeletal muscle cell breakdown that causes the release of potentially toxic substances into the circulation. There is no consensus on the definition of rhabdomyolysis. Some clinicians characterize it by the elevation of serum creatine kinase $(\mathrm{CK})$ activity to at least ten times the upper limit of normal followed by a quick decline; while others consider a smaller increase in CK elevation (>5 times) sufficient for a diagnosis of rhabdomyolysis [1]. The diagnosis of rhabdomyolysis is dependent on the recognition of symptoms of muscle pain and weakness, the detection of current myoglobinuria or recent history, and elevated CK after ruling out other causes [2]. The severity of rhabdomyolysis ranges from asymptomatic elevation of $\mathrm{CK}$ to the life-threatening complications of acute renal failure and the development of severe electrolyte abnormalities. Theprincipal therapeutic goal is to recognize and treat complications as soon as possible, particularly electrolyte abnormalities and acute renal failure [3]. Drug-induced rhabdomyolysis is commonly thought of as an adverse effect of HMG CoA reductase inhibitor (Statin) therapy and typically qualified by a classical triad of symptoms including skeletal muscle injury, pigmented urine, and some level of renal dysfunction [4]. The American College of Cardiology/American Heart Association/National Heart, Lung and Blood Institute Clinical Advisory on the use and safety of statins defined statin-induced rhabdomyolysis as a CK elevation greater than ten times the upper limit of normal [5] [6].

A literature review of case reports, case series, and journal articles have shown the use of alcohol and other prescription medications have a higher incidence in causing rhabdomyolysis, and as many as $60 \%$ of patients have multiple concomitant etiologic factors attributing to a diagnosis of rhabdomyolysis [2] [4] [7] [8]. Trimethoprim-sulfamethoxazole (SMX-TMP) is an oral synthetic antibacterial combination product commonly used to treat urinary tract infections. According to the package insert, it should be given with caution to patients with impaired renal or hepatic function, to those with possible folate deficiency (e.g., the elderly, chronic alcoholics, patients receiving anticonvulsant therapy, patients with malabsorption syndrome, and patients in malnutrition states) [9]. The Food \& Drug Administration reports that rhabdomyolysis can be found among people who take SMX-TMP, especially for people who are male, greater than 60 years old, have been taking the drug for less than a month, who also take the medication omeprazole, or have the human immunodeficiency virus (HIV) infection [9]. Our review of the literature found most of the reported cases being in immunocompromised patients with HIV infection [10] [11] [12], or allogeneic stem cell transplant recipient [11] [13]. To the best of our knowledge, our patient is the third case of SMX-TMP-induced rhabdomyolysis in an immunocompetent patient, and the second of the immunocompetent patient to have multiple attributing factors [14] [15]. Verbal consent was obtained from the patient to discuss her case. 


\section{Case Summaries}

A 43-year-old African American female, with no significant family history or past medical history, presented to the emergency department (ED) on day 8 of worsening bilateral leg pain after taking five doses of SMX-TMP $800-160 \mathrm{mg}$ for a suspected urinary tract infection. The patient stated that after two days of SMX-TMP therapy the initiation and intensifying leg pain caused her to return to her primary care physician where she was re-evaluated, and SMX-TMP was replaced with ciprofloxacin. Her leg pain continued to intensify, and she presented to our ED rating her painasa 10 out of 10 , stating the pain was alleviated by nothing, aggravated by bearing weight and she had never experienced similar symptoms in the past.

On presentation to our ED, she was hemodynamically stable with blood pressure at $125 / 79 \mathrm{mmHg}$, pulse at $90 / \mathrm{min}$, and afebrile with a core body temperature of $98^{\circ} \mathrm{F}$. The patient admitted to daily alcohol consumption at least two vodka drinks per day, 30 pack-year smoking history, and current medication vortioxetine $10 \mathrm{mg}$ per day for the treatment of depression. The patient denied any recent trauma or use of dietary supplements. Urineand blood drug screen ruled out illicit drug use, as well as acetaminophen and salicylate toxicities. She had no history of seizures. The initial lab analysis showed an elevated CK 26, 231 units per liter (U/L) (normal range, $30-223 \mathrm{U} / \mathrm{L}$ ), aspartate transaminase 352 $\mathrm{U} / \mathrm{L}$ (AST; normal range, $10-14 \mathrm{U} / \mathrm{L}$ ), alanine transaminase $111 \mathrm{U} / \mathrm{L}$ (ALT; normal range, $10-40 \mathrm{U} / \mathrm{L}$ ) and a normal serum creatinine $1.0 \mathrm{mg} / \mathrm{dL}(\mathrm{SCr}$; normal range, $0.6-1.2 \mathrm{mg} / \mathrm{dL}$ ). Upon physical examination in the ED the patient showed signs of bilateral leg tenderness, no signs of numbness, showed the full range of motion in all extremities and was able to bear weight fully.

Ten hours after the presentation, the patient was admitted with an increase in CK to $38,360 \mathrm{U} / \mathrm{L}$, AST to $514 \mathrm{U} / \mathrm{L}$, and ALT to $168 \mathrm{U} / \mathrm{L}$. She was initiated on intravenous fluids plus thiamine and folic acid supplementation. SMX-TMP discontinued and vortioxetine $10 \mathrm{mg}$ per day was continued until hospital day 5 . A urinalysis was positive for protein, negative for blood, yellow in color and clear in appearance. All viral titers, serology tests, and bacterial cultures were negative. On hospital day 2, the patient's CK peaked at 45,020 U/L then trended downwards as shown in Figure 1. Note, her SCr remained within normal limits during the entire hospital stay. The patient showed improvement in lower extremity pain and tenderness and was discharged on hospital day 8 with a $\mathrm{CK}$ $2809 \mathrm{U} / \mathrm{L}$.

\section{Discussion}

The first case series (Case 1 in Table 1) that is of an immunocompetent patient with SMX-TMP-induced rhabdomyolysis by Ainapurapu and Kanakadandi was very similar to our patient in that they were both females in their early 40 's, being treated empirically with SMX-TMP for a suspected UTI and experiences an onset of bilateral leg pain on day 2 of therapy [14]. However, no confounding 


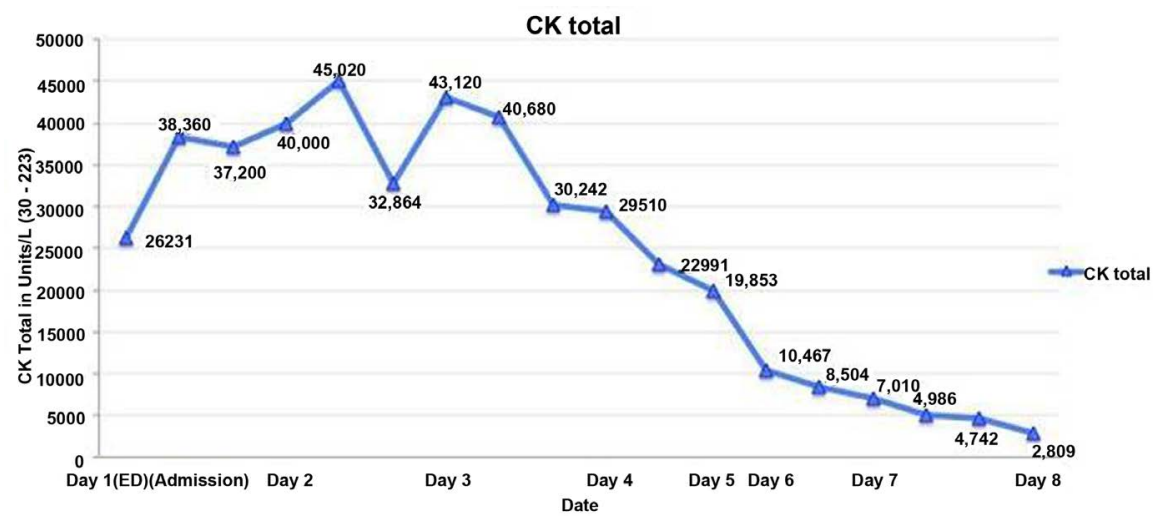

Figure 1. Patient's serum creatine kinase (CK) levels during hospital stay (normal range, $30-223 \mathrm{U} / \mathrm{L})$.

Table 1. Comparison of case reports of SMX-TMP-induced rhabdomyolysis in immunocompetent patients.

\begin{tabular}{|c|c|c|c|c|c|c|c|c|}
\hline $\begin{array}{l}\text { Case (Reference } \\
\text { number) }\end{array}$ & $\begin{array}{l}\text { Age } \\
\text { (Yrs) }\end{array}$ & Sex & $\begin{array}{l}\text { Indication for } \\
\text { SMX-TMP, } \\
\text { number of } \\
\text { doses }\end{array}$ & $\begin{array}{l}\text { Rhabdomyolysis-related } \\
\text { signs, symptoms, and } \\
\text { laboratory findings }\end{array}$ & $\begin{array}{l}\text { Days until } \\
\text { symptom } \\
\text { onset }\end{array}$ & $\begin{array}{c}\text { Creatine } \\
\text { Kinase Level } \\
(\mathrm{U} / \mathrm{L}) \max \end{array}$ & $\begin{array}{l}\text { Days until recovery } \\
\text { post positive } \\
\text { dechallenge, } \\
\text { CK }(\mathrm{U} / \mathrm{L}) \text { at recovery }\end{array}$ & $\begin{array}{l}\text { Confounding } \\
\text { etiologic factors }\end{array}$ \\
\hline $\begin{array}{c}1 \\
(14)\end{array}$ & 40 & $\mathrm{~F}$ & $\mathrm{UTI}^{[\mathrm{A}]}, 4$ & $\begin{array}{c}\text { Muscle tenderness, } \\
\text { Myalgia, Weakness, SCr } \\
1.5 \mathrm{mg} / \mathrm{dL} \\
(0.6-1.1 \mathrm{mg} / \mathrm{dL})\end{array}$ & 2 & 20063 & NA, 760 & None reported \\
\hline $\begin{array}{c}2 \\
(15)\end{array}$ & 64 & M & $\mathrm{UTI}^{[\mathrm{B}]}, 7$ & $\begin{array}{l}\text { Myoglobinuria, Myalgia, } \\
\text { Tea-colored urine, } \\
\text { elevated transaminases, } \\
\text { lactate dehydrogenase, } \\
\text { mild acidosis, } \\
\text { hyponatremia, } \\
\text { hypocalcemia, } \\
\text { hyperuricemia }\end{array}$ & $5[2] \dagger$ & 64691 & 6 days, 4720 & $\begin{array}{l}\text { NSAIDs }^{*} \\
\text { CYP2C9 } \\
\text { inhibition }\end{array}$ \\
\hline $\begin{array}{l}3 \text { (Our patient } \\
\text { report) }\end{array}$ & 43 & $\mathrm{~F}$ & $\mathrm{UTI}^{[\mathrm{C}]}, 5$ & $\begin{array}{l}\text { Proteinuria, Myalgia, } \\
\text { elevated transaminases, } \\
\text { hyponatremia, } \\
\text { hypocalcemia }\end{array}$ & 2 & 45020 & 8 days, 2809 & $\begin{array}{l}\text { ¥Alcoholism, } \\
\text { atypical } \\
\text { antidepressant }\end{array}$ \\
\hline
\end{tabular}

NA = data not available; ${ }^{[A]}$ : empiric treatment for presumed UTI. Dose and frequency not specified. ${ }^{[\mathrm{B}]}$ : Self-medicated Biseptol (trimethoprim-sulfamethoxazole $40 / 800 \mathrm{mg}$ ) 3 tablets per day for "self-diagnosed" UTI ${ }^{[C]}$ empiric treatment for presumed UTI. Bactrim DS (sulfamethoxazole-trimethoprim 800/160 mg) 1 tablet twice per day. $\dagger$ : Days from initiation of aggravating factor to worsening symptoms. *: Ibuprofen $200 \mathrm{mg}$ per day, celecoxib $200 \mathrm{mg}$ per day, piroxicam $20 \mathrm{mg}$ per day, Algocalmine (sodium metamizole $500 \mathrm{mg}$ ) 2 pills per day, and Antineuralgic (acetylsalicylic acid $250 \mathrm{mg}+$ phenacetine $150 \mathrm{mg}+$ caffeine 50 $\mathrm{mg}) 2$ tablets per day. He also consulted a rheumatology specialist, who prescribed him parenteral NSAIDs as follows: ketorolac $30 \mathrm{mg} / \mathrm{mL}$, two vials per day, and meloxicam $15 \mathrm{mg}$, two vials per day. \$: Two vodka drinks per day; vortioxetine $10 \mathrm{nmg}$ daily.

etiologic factors were reported. The patient in the case published by Petrov et al. (Case 2 in Table 1), is also similar to our case due to the presence of confounding etiologic factors [15] However, the differences in the series of events are notable. The patient was initiatedon SMX-TMP therapy leading to the development of bilateral leg pain, and then the patient was introduced to a non-steroidal anti-inflammatory treatment which could have acted as an aggravating or confounding factor causing the leg pain to intensify and an increase in CK from 1524U/L to $64691 \mathrm{U} / \mathrm{L}$. Case 3 in Table 1 is our case report. Our patient's confounding etiologic factors, chronic alcohol consumption, and concomitant atyp- 
ical antidepressant therapy, were present prior the initiation of the SMX-TMP, acting as predisposing risk factors.

Trimethoprim-sulfamethoxazole is the most likely offending agent to cause rhabdomyolysis in our patient. However, our patient's chronic alcohol use and concomitant atypical antidepressant therapy should be considered as possible predisposing etiologic risk factors. Our patient's chronic alcoholism could have caused malnutrition which are known predisposing factors to rhabdomyolysis [16]. Vortioxetine acts as a serotonin reuptake inhibitor and a serotonin antagonist, which are both mechanisms of known myotoxic agents [17]. Our case report is consistent with the findings that a diagnosis of rhabdomyolysis is commonly multifactorial, and most patients without underlying myopathy require multiple insults.

\section{Conclusion}

We concluded that our patient's intensifying bilateral leg pain accompanied by an increased CK level was due to direct skeletal muscle injury caused by SMXTMP because of the following reasons: a) the close temporal relationship between SMX-TMP exposure and the development of rhabdomyolysis followed by recovery when the drug was withdrawn (positive dechallenge); b) SMX-TMP has been associated with toxin-induced rhabdomyolysis in an immunocompetent patient both with and without attributing etiologic factors; c) other bacterial, viral, toxic and pathologic etiologies were assessed and ruled out. As most cases of rhabdomyolysis have multiple causal factors. Clinicians should be mindful of this complication and predisposing factors because rhabdomyolysis is not isolated to immunocompromised patients as our case report has shown. Proper drug selection which includes patient specific parameter including recognizing risk factors is a fundamental role that physicians and pharmacists play in preventing possible cases rhabdomyolysis.

\section{Disclaimers}

The views expressed in the submitted article are his or her own and not an official position of the institution or funder.

\section{Conflict of Interest}

Authors of this presentation have the following to disclose concerning possible financial or personal relationships with commercial entities that may have a direct or indirect interest in the subject matter of this presentation.

\section{References}

[1] Zutt, R., van der Kooi, A.J., Linthorst, G.E., Wanders, R.J.A. and de Visser, M. (2014) Rhabdomyolysis: Review of the Literature. Neuromuscular Disorders (NMD), 24, 651-659. https://doi.org/10.1016/j.nmd.2014.05.005

[2] Allison, R.C. and Lawrence Bedsole, D. (2003) The Other Medical Causes of Rhab- 
domyolysis. The American Journal of the Medical Sciences, 326, 79-88.

https://doi.org/10.1097/00000441-200308000-00005

[3] Vale, A. (2016) Rhabdomyolysis. Medicine (Baltimore), 44, 93-94.

https://doi.org/10.1016/j.mpmed.2015.11.002

[4] Coco, T.J. and Klasner, A.E. (2004) Drug-Induced Rhabdomyolysis. Current Opinion in Pediatrics, 16, 206-210. https://doi.org/10.1097/00008480-200404000-00017

[5] Antons, K.A., Williams, C.D., Baker, S.K. and Phillips, P.S. (2006) Clinical Perspectives of Statin-Induced Rhabdomyolysis. The American Journal of Medicine, 119, 400-409. https://doi.org/10.1016/j.amjmed.2006.02.007

[6] Members, W.C., Pasternak, R.C., Smith, S.C., et al. (2002) ACC/AHA/NHLBI Clinical Advisory on the Use and Safety of Statins. Stroke, 33, 2337-2341. https://doi.org/10.1161/01.str.0000034125.94759.41

[7] Melli, G., Chaudhry, V. and Cornblath, D.R. (2005) Rhabdomyolysis: An Evaluation of 475 Hospitalized Patients. Medicine (Baltimore), 84, 377-385. https://doi.org/10.1097/01.md.0000188565.48918.41

[8] Gabow, P.A., Kaehny, W.D. and Kelleher, S.P. (1982) The Spectrum of Rhabdomyolysis. Medicine (Baltimore), 61, 141-152. https://doi.org/10.1097/00005792-198205000-00002

[9] Will You Have Rhabdomyolysis with Bactrim-From FDA Reports-eHealthMe. https://www.ehealthme.com/ds/bactrim/rhabdomyolysis/

[10] Walker, S., Norwood, J., Thornton, C. and Schaberg, D. (2006) Trimethoprim-Sulfamethoxazole Associated Rhabdomyolysis in a Patient with AIDS: Case Report and Review of the Literature. The American Journal of the Medical Sciences, 331, 339341. https://doi.org/10.1097/00000441-200606000-00011

[11] Augustyn, A., Lisa Alattar, M. and Naina, H. (2015) Rhabdomyolysis Due to Trimethoprim-Sulfamethoxazole Administration Following a Hematopoietic Stem Cell Transplant. Case Reports in Oncological Medicine.

[12] Huang, J.C., Gold, S., McManus, K.A. and Wispelwey, B. (2013) Case Report: Rhabdomyolysis in the Setting of Acute Human Immunodeficiency Virus Infection. Case Reports in Clinical Medicine, 2, 198. https://doi.org/10.4236/crcm.2013.23054

[13] Kiel, P.J., Dickmeyer, N. and Schwartz, J.E. (2010) Trimethoprim-Sulfamethoxazole-Induced Rhabdomyolysis in an Allogeneic Stem Cell Transplant Patient. Transplant Infectious Disease, 12, 451-454. https://doi.org/10.1111/j.1399-3062.2010.00524.x

[14] Ainapurapu, B. and Kanakadandi, U.B. (2014) Trimethoprim-Sulfamethoxazole Induced Rhabdomyolysis. American Journal of Therapeutics, 21, e78-e79. https://doi.org/10.1097/MJT.0b013e31824567fe

[15] Petrov, M., Yatsynovich, Y. and Lionte, C. (2015) An Unusual Cause of Rhabdomyolysis in Emergency Setting: Challenges of Diagnosis. American Journal of Emergency Medicine, 33, 123.e1-123.e3. https://doi.org/10.1016/j.ajem.2014.05.041

[16] Zimmerman, J.L. and Shen, M.C. (2013) Rhabdomyolysis. Chest, 144, 1058-1065. https://doi.org/10.1378/chest.12-2016

[17] Huang, S.-S., Yang, H.-Y., Lin, Y.-C. and Chan, C.-H. (2012) Low-Dose Venlafaxine-Induced Severe Rhabdomyolysis: A Case Report. General Hospital Psychiatry, 34, 436.e5-7. https://doi.org/10.1016/j.genhosppsych.2012.01.016 